\title{
Coefficients of variation in timing of the classically conditioned eyeblink in rabbits
}

\author{
NATASHA E. WHITE and E. JAMES KEHOE \\ University of New South Wales, Sydney, Australia \\ and \\ JUNE-SEEK CHOI and JOHN W. MOORE \\ University of Massachusetts, Amherst, Massachusetts
}

\begin{abstract}
The time course of the conditioned response (CR) in rabbit eyeblink conditioning is highly attuned to the interstimulus interval (ISI) between the onsets of the conditioned stimulus and unconditioned stimulus (US). In the present study, we reexamined data from a large number of experiments in two separate laboratories to determine whether CR timing conformed to a constant ratio analogous to Weber's law. Specifically, the mean and standard deviations $(S D s)$ in the timing of the CR's peak were used to calculate coefficients of variation (CV) for ISIs ranging from 200 to $1,300 \mathrm{msec}$. Both the mean and standard deviations increased as the ISI was increased, but their ratio (the CV) appeared to remain constant. The average of the estimates was $0.12(S D=0.045)$. The results are discussed with respect to real-time models of classical conditioning and scalar expectancy theory.
\end{abstract}

The time course of the conditioned response (CR) in rabbit eyelid preparations is highly attuned to the interstimulus interval (ISI) between the onset of the conditioned stimulus (CS) and the onset of the unconditioned stimulus (US). The rabbit learns not only that the CS is followed by the US, but it also learns when the US will occur. Most notably, the maximal closure of the eyelid CR (the CR peak latency) roughly coincides with the time of US delivery across a wide range of ISIs (see, e.g., Gormezano, Kehoe, \& Marshall, 1983; Smith, 1968). The time at which the initiation of the CR occurs is also dynamically linked to the ISI. That is, during acquisition of the CR, its time of initiation decreases to roughly the midpoint of the ISI (Gormezano et al., 1983).

The timing of CR peaks, as well as other features of the CR, has been the focus of "real-time" models of conditioning (e.g., Buonomano \& Mauk, 1994; Desmond \& Moore, 1988; Grossberg \& Schmajuk, 1989; Kehoe, Horne, Macrae, \& Horne, 1993; Moore \& Choi, 1997; Moore, Choi, \& Barto, 1996; Moore, Choi, \& Brunzell, 1998). These models assume that timing of the CR is mediated by a cascade of activity from neuron-like elements. The CS and the US are inputs to a neuron-like processor responsible for learning and CR production. The ISI is thought to be represented through the progressive activation of an array of a certain number of neurons $(N)$. This number is usually assumed to be proportional to the du-

Preparation of this manuscript was supported by Australian Research Council Grant A79800067 to E.J.K. and by Grant MH57893 to J.W.M. We thank Jordan S. Marks and Vanessa E. Castagna for their assistance in data collection and analysis. Correspondence should be sent to E. J. Kehoe, School of Psychology, University of New South Wales, UNSW Sydney 2052, Australia (e-mail: j.kehoe@unsw.edu.au). ration of the ISI. The ISI can therefore be understood in terms of the number of elements activated in the array up to the time of US occurrence. Each element is assumed to develop associative strength in proportion to its level of activation at the time of the US. Therefore, the elements that occur in the same time zone as the US gain the greatest associative strength. During subsequent presentations of the CS, the amplitude of the CR at any point in time reflects the summation of the associative strengths of the elements in that time zone, and the CR's peak tends to occur at the time of US delivery, at which point there has been the greatest overlap of elements with the US.

Although real-time models have focused on the time course of the response in classical conditioning, the same models can be regarded as part of the larger body of research and theory concerning the psychophysics of time judgments. From this perspective, the main question concerns whether the timing of CRs follows any particular psychophysical function. In turn, identification of this function may shed light on the underlying distribution of elements, on which real-time models so heavily rely.

A significant body of research in both animal and human timing has accumulated over the past 30 years. In many of these studies, the timing of the target response has appeared to conform to a psychophysical function analogous to Weber's law. This psychophysical function states that the standard deviation of time estimates $(S)$ is directly proportional to their mean $(M)$. This proportionality implies a constant coefficient of variation $(S / M)$ across changes in absolute time.

The Weber's law property is a basic assumption underlying many theories of timing (e.g., Gibbon, 1977; Killeen \& Fetterman, 1988; Staddon \& Higa, 1999). However, clear and robust evidence for Weber's law is 
not as widespread as might be expected, given its pivotal role in key theories. Evidence for Weber's law has been obtained in operant experiments with rats (Church \& Deluty, 1977; Church, Miller, Meck, \& Gibbon, 1991) and pigeons (Cheng \& Roberts, 1991; Schneider, 1969; Stubbs, 1968). However, there are a small group of animal timediscrimination studies that either have not shown evidence for Weber's law or have produced results that could only be explained by a more complicated version of it (e.g., Church, Getty, \& Lerner, 1976; Innis \& Staddon, 1971; Zeiler, 1991).

From the initial development of Weber's law for psychophysical judgments in general, it has been acknowledged that it does not hold at extreme values of physical discriminations. With respect to timing in particular, this constraint on Weber's law and its analogues also holds. Data inconsistent with Weber's law are commonly found at very short and very long time intervals, especially in humans (see Church et al., 1976; Fetterman \& Killeen, 1992).

Even in the middle range of time intervals in any one procedure, there are some constraints on the ubiquity of the Weber's law property of timing. Lejeune and Wearden (1991) carried out a comparative analysis of time discrimination over a range of species in operant procedures. There was a wide range of values at which rats, mice, pigeons, and doves exhibited a constant coefficient of variation. Nevertheless, in several mammal species and also in some pigeons, Tilapia fish, and freshwater turtles, the coefficient of variation (CV) increased with increases in a fixed-interval schedule. In contrast, studies of timing in humans have tended to show a decrease in the $\mathrm{CV}$ as the target interval increases (Treisman, 1963; Zeiler, 1991).

One area in which the Weber's law property has been less widely tested is classical conditioning. Gibbon and Balsam (1981) reviewed a number of studies involving pigeon autoshaping. They found what they described as a Pavlovian Weber's law, or scalar timing; that is, for a given accuracy of timing, the ratio between the intertrial interval (ITI) and the ISI was relatively constant (Gibbon, 1977, 1991). However, they found a wide range of variability in the data, especially at the extremes. Other than these autoshaping findings, results on the psychophysics of timing in classical conditioning are lacking. To help fill this gap, we reexamined peak latencies that were recorded during rabbit eyeblink experiments conducted in our two respective laboratories.

\section{METHOD}

Data were collated from four experiments conducted at the University of New South Wales (UNSW) that examined the inner eyelid-the nictitating membrane (NM)-response. Each group of rabbits was naive and trained with a single, fixed ISI. There were 38 rabbits trained with a $200-\mathrm{msec}$ ISI 7 from Kehoe \& Napier, 1991, 15 from Kehoe, Horne, \& Macrae, 1995, Experiment 1, and 16 from Kehoe et al., 1995, Experiment 2). An additional 32 rabbits were trained with a $600-\mathrm{msec}$ ISI $(8,16$, and 8 rabbits from each of the experiments mentioned above, respectively). There were eight rabbits trained with a 400-msec ISI (Kehoe et al., 1995). Additionally, there were three groups of 8 rabbits trained with 300 msec, 800-msec, and 1,300-msec ISIs, respectively (Kehoe, 1986). In all experiments, the ITI was variable, with a uniform distribution with a range of $53-63 \mathrm{sec}(M=58 \mathrm{sec})$.

Data were also collated from two studies conducted at the University of Massachusetts, using the upper eyelid response. Specifically, for 28 rabbits in the first study, a single CS was paired with the US at ISIs of $300 \mathrm{msec}$ or $700 \mathrm{msec}$ on a randomly intermixed basis. For 12 of these rabbits, the CS duration was $800 \mathrm{msec}$, and for the remainder, the CS duration was $300 \mathrm{msec}$. (Preliminary analyses failed to reveal any differences related to CS duration.) Data were also collated for 3 rabbits in the second study, in which each presentation of the CS contained two US presentations, one to each eye at staggered times. The rabbits were trained with a fixed $300-\mathrm{msec}$ ISI to the right eye, and, on the same trial, the left eye was presented with a US that began at a $600-\mathrm{msec}$ ISI and progressively decreased over trials (Choi \& Moore, 1994).

The apparatus and recording procedure for the eyelid responses were patterned after those of Gormezano (1966). For the NM response, a small wire hook was attached to a silk loop sutured in the NM of the animal's right eye. The other end of the hook contained a loop that fit over the curved end of an L-shaped piano wire crank that operated a photoelectric transducer (Gormezano \& Gibbs, 1988). The signal from the transducer was amplified and transmitted to an analog/digital converter installed in a computer. For the upper-eyelid response, a nylon loop was sutured into the right eyelid. The loop was connected to a potentiometer via a metal hook and thread. On CS-alone test trials, a CR was scored for any extension of the NM exceeding $0.5 \mathrm{~mm}$ initiated during the CS. The peak latency of the $C R$ was the point in time at which the $C R$ reached its maximal extension (Marshall-Goodell, Schreurs, \& Gormezano, 1982).

\section{Results}

Peak latencies of CRs on all CS-alone test trials were analyzed. Trials in which no eyelid movement was detectable were removed from the analysis. For each rabbit, the mean peak latency and the $S D$ of the peak latency on CS-alone test trials were calculated. A CV was calculated for each rabbit by dividing the $S D$ by the mean peak latency. For each ISI, a $95 \%$ confidence interval for the coefficient of variation was calculated using the data from the rabbits trained using that ISI.

Table 1 shows the results for the UNSW studies. For each ISI, the table shows the average across animals for the mean peak latency (MPL), the $S D$, the CV (SD/MPL), the upper limit of the confidence interval for the $\mathrm{CV}$ (CIU), the lower limit of the confidence interval (CIL), and the number of rabbits that contributed to the data $(N)$. The data in Table 1 confirm previous findings that the peaks of the CRs were aligned with the ISI. However, the placement of the peak varied slightly across ISIs. For ISIs of $600 \mathrm{msec}$ and less, the mean peak latency was longer than the target ISI. For longer ISIs, the mean peak latency was shorter than the target ISI.

Both the MPL and $S D$ increased as a function of ISI. An analysis of variance (ANOVA) was carried out. The analysis revealed that both measures increased significantly in a linear fashion $[F(1,96)=3,605.92$ for the MPL, $F(1,96)=49.36$ for the $S D]$. There was no evidence of a quadratic trend in either measure $[F(1,96)=1.29$ for the MPL, $F<1$ for the $S D$ ]. 
Table 1

Measures of Conditioned Response Peak Timing as a Function of Interstimulus Interval (ISI) in Milliseconds in UNSW Nictitating Membrane Experiments

\begin{tabular}{rrrrrrr}
\hline ISI & MPL & SD & CV & CIL & CIU & $N$ \\
\hline 200 & 245 & 61 & 0.24 & 0.16 & 0.31 & 38 \\
300 & 345 & 30 & 0.09 & 0.06 & 0.12 & 8 \\
400 & 435 & 67 & 0.16 & 0.10 & 0.21 & 8 \\
600 & 652 & 106 & 0.16 & 0.14 & 0.19 & 32 \\
800 & 784 & 109 & 0.14 & 0.09 & 0.20 & 8 \\
1,300 & 1,249 & 201 & 0.17 & 0.09 & 0.25 & 8 \\
\hline
\end{tabular}

Note - ISI is CS-US ISI in milliseconds; MPL is mean peak latency, and $S D$ is its standard deviation; $C V$ is the coefficient of variation (SD/MPL); CIL and CIU are the lower and upper limits of the $95 \%$ confidence interval for the $\mathrm{CV} ; N$ is the number of rabbits.

Inspection of the CVs reveals that for ISI values of $400 \mathrm{msec}$ and above, the CV hovered between 0.14 and 0.17 . However, at the shorter ISIs, the CVs deviated from this pattern, but in opposite directions. The 200-msec ISI produced a CV of 0.24 , but the $300-\mathrm{msec}$ ISI produced a $\mathrm{CV}$ of 0.09 . However, these apparent differences failed to reach statistical significance. An ANOVA carried out on the CVs failed to reveal any evidence for a linear or a quadratic trend in the CVs across ISIs $(F \mathrm{~s}<1)$. Hence, on the basis of this statistical test, there was no foundation for rejecting the null hypothesis that the CVs were constant across ISIs from 200 to $1,300 \mathrm{msec}$.

Recall that the first University of Massachusetts experiment used two ISIs-300 and $700 \mathrm{msec}$--that were presented randomly to the same group of rabbits with the same CS-US pairing. As a consequence, the rabbits developed two peaks that correlated with the two ISIs. The upper two rows of Table 2 show the results of the measures for each of these ISIs. It can be seen in Table 2 that both MPLs settled at values slightly longer than the ISIs. In both cases, the $\mathrm{CV}$ was equal at a level of 0.10 .

The results from the second University of Massachusetts experiment showed that the rabbits learned to respond separately with each eye to the same CS. The lower rows of Table 2 display the results for the fixed 300 -msec ISI presented to the right eye and the seven different ISIs presented to the left eye. For the $300-\mathrm{msec}$ ISI to the right eye, the MPL was $342 \mathrm{msec}$. Responding by the left eye moved in time as the ISI was moved, always remaining slightly longer than the ISI. The CVs in this experiment once again remained relatively constant. The range of CVs was from 0.06 to 0.13 , with a mean of 0.10 . An ANOVA was carried out on the CVs computed for the ISIs presented to the left eye. Any apparent differences were not significant $(F<1)$.

In order to summarize the results from the two laboratories, the mean CVs for each ISI along with their corresponding $95 \%$ confidence intervals, were plotted (see Figure 1). (The distributions of the peak latencies were approximately symmetric, although a tail extending to the shorter values appeared for the longer ISIs; cf. Kehoe et al., 1995.) An area was drawn that was touched by the confidence intervals of all groups. Thus, it can be seen that the CVs of all groups from both laboratories occurred in an interval spanning 0.08 and 0.16 . The only group that might not have fit well into this interval was the 200 msec ISI group.

\section{DISCUSSION}

Across groups, the CV appeared to fall within the $0.08-0.16$ range. Evidence to suggest that there were any statistically significant differences among the ISIs used in each set of experiments was not forthcoming. Only the $200-\mathrm{msec}$ ISI produced a relatively large CV. This ISI is slightly shorter than the $250-\mathrm{msec}$ ISI that is commonly regarded as the optimal value for rabbit eyelid conditioning (Gormezano et al., 1983). Hence, the 200msec ISI might be close to a lower boundary for Weber's law, as applied to timing of the rabbit eyelid CR. However, for the ISIs longer than $200 \mathrm{msec}$, the relative constancy in the CVs does support application of an analogue of Weber's law to classical conditioning.

The level of acuity for the rabbit eyeblink appears to be much the same as that seen in human intervalproduction experiments (Wearden, 1991). The human CVs for a wide range of intervals $(0.5-32 \mathrm{sec})$ range from 0.10 to 0.16 , which is virtually identical to the range in which the rabbit eyeblink CVs occurred. However, in comparison with the findings in operant interval-discrimination studies with animals, the CVs obtained in our experiments were lower. The mean $\mathrm{CV}$ over all of our experiments was 0.12 , whereas in operant studies average CVs tend to be between 0.16 and 0.80 (e.g., Gibbon, 1991; Lejeune \& Wearden, 1991; Zeiler, 1991). This range of estimates may be divided into "higher" animals (mammals), which tend to produce CVs averaging around 0.30 , and "lower" animals (e.g., birds, fish, and turtles), which tend to produce CVs above 0.50 .

Table 2

\begin{tabular}{|c|c|c|c|c|c|c|}
\hline ISI & $\mathrm{MPL}$ & $S D$ & $\mathrm{CV}$ & $\mathrm{ClL}$ & CIU & $N$ \\
\hline \multicolumn{7}{|c|}{ Experiment 1} \\
\hline 300 & 379 & 39 & 0.10 & 0.09 & 0.11 & 28 \\
\hline 700 & 770 & 79 & 0.10 & 0.09 & 0.12 & 28 \\
\hline \multicolumn{7}{|c|}{ Experiment 2} \\
\hline \multicolumn{7}{|c|}{ Right Eye } \\
\hline 300 & 342 & 31 & 0.09 & 0.07 & 0.11 & 3 \\
\hline \multicolumn{7}{|c|}{ Left Eye } \\
\hline 300 & 348 & 32 & 0.09 & 0.07 & 0.12 & 3 \\
\hline 310 & 364 & 44 & 0.12 & 0.08 & 0.16 & 3 \\
\hline 323 & 352 & 45 & 0.13 & 0.06 & 0.19 & 3 \\
\hline 342 & 368 & 29 & 0.08 & 0.07 & 0.08 & 3 \\
\hline 379 & 416 & 33 & 0.08 & 0.07 & 0.09 & 3 \\
\hline 454 & 484 & 31 & 0.06 & 0.05 & 0.08 & 3 \\
\hline 604 & 649 & 73 & 0.11 & 0.04 & 0.19 & 3 \\
\hline
\end{tabular}

Note-ISI is CS-US ISI in milliseconds; MPL is mean peak latency, and $S D$ is the standard deviation; $\mathrm{CV}$ is the coefficient of variation (SD/MPL): CIL and CIU are the lower and upper limits of the $95 \%$ confidence interval for the $\mathrm{CV} ; N$ is the number of rabbits. 


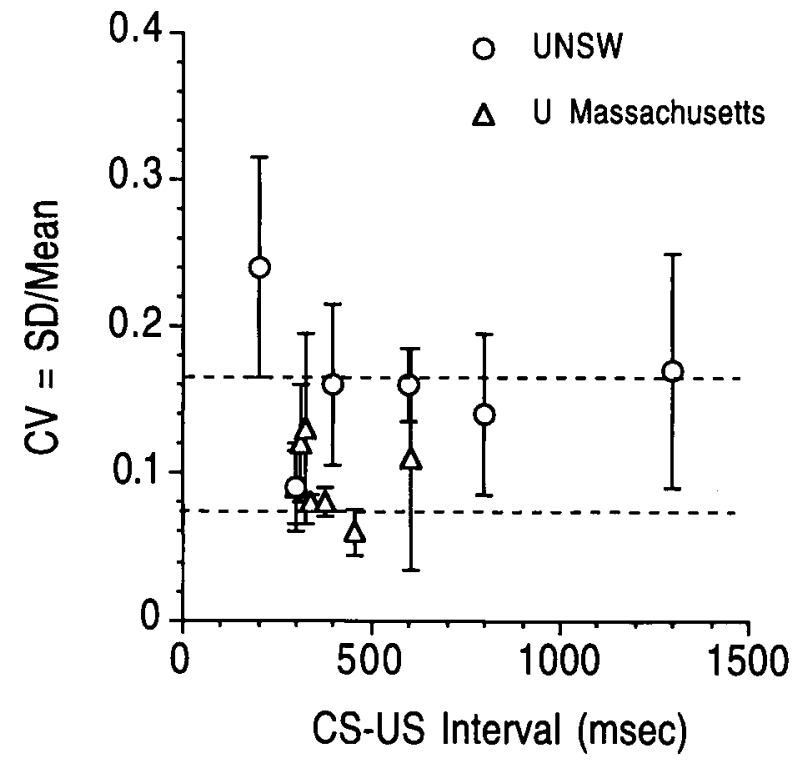

Figure 1. Mean coefficients of variation (CV) as a function of CS-US interstimulus interval (ISI in milliseconds). The vertical bars represent the $95 \%$ confidence interval $( \pm 1.96 S E)$ around each mean.

Regardless of any differences in the acuity of timing, the present findings converged with those of previous studies of timing in that there was a changing relationship between the judgment and the target interval. There tends to be an overestimation when the target interval is short, and an underestimation when the target interval becomes longer (Catania, 1970; Treisman, 1963; Zeiler, 1991). This pattern was found in the UNSW studies, in which a wide range of ISIs was used. Specifically, the MPL was longer than the ISI when the ISI was $600 \mathrm{msec}$ or less. The MPL became shorter than the ISI at values of 800 and 1,300 msec.

The changing relationship between the ISI and the MPL coupled with a constant relationship between the ISI and the $\mathrm{CV}$ suggests that there are joint changes in the MPL and the $S D$ as the ISI increases. As the MPL decreases relative to the ISI, there is a corresponding increase in the relative $S D$. Even though the present data show that this increase takes place, it is intriguing that both the constant error and random error changed in such a way as to yield a constant CV. However, it is worth noting that these joint changes may not always occur in synchrony. In some operant studies, there are slight increases in the $\mathrm{CV}$ as the target interval increases (Lejeune \& Wearden, 1991).

Given the prominence of scalar expectancy theory (SET; Gibbon, 1977, 1991), it is of interest to examine whether this theory can account for the present results. SET claims that there should be a constant level of accuracy for a given ISI/ITI ratio. Gibbon and Balsam (1981) found evidence supporting this hypothesis in pigeon autoshaping with ISIs and ITIs that were both in the range of seconds to tens of seconds. The present results show that the level of accuracy remained relatively constant as the ISI changed, even though the ITI remained the same. However, the absence of scalar timing may arise from two sources. First, in rabbit eyeblink conditioning, the ITI is usually two orders of magnitude greater than the ISI. Hence, large variations in the ISI only marginally alter the ISI/ITI ratio. (However, an attempt to extend the ISI to large values would result in little or no acquisition of CRs; Gormezano et al., 1983; Kehoe, Cool, \& Gormezano, 1991.) Second, rabbit eyeblink preparations are relatively insensitive to manipulations of the ITI within a training session (Brelsford \& Theios, 1965; Frey \& Misfeldt, 1967; Mis, Andrews, \& Salafia, 1970; Mitchell, 1974; Salafia, Mis, Terry, Bartosiak, \& Daston, 1973; Salafia, Terry, \& Daston, 1975). Hence, SET may not be suitable for studying rabbit eyelid conditioning, or vice versa.

The evidence accumulated in this study for a constant $\mathrm{CV}$ in rabbit eyeblink conditioning also challenges realtime models of classical conditioning. For example, a complete-serial-compound model describes the ISI in terms of the number of elements in the array up to the time of US occurrence (Moore \& Choi, 1997; Moore et al., 1998). The model makes the following assumptions: (1) The number of elements scale proportionally to the ISI, (2) the delay imposed by each element is a random variable with some distribution that is stationary and homogeneous across all synapses in the array, and (3) all synaptic delays are independent. From these assumptions, variance in the distribution of CR peak times becomes the sum of the variances of the $N$ elements that span the ISI. Hence, this real-time model predicts a CV equal to the square root of $N$ multiplied by the $S D$ over $N$. The $\mathrm{CV}$ is thus not constant across all values of $N$ and so is not consistent with either Weber's law or the findings of the present study.

One way for such a model to account for the constant $\mathrm{CV}$ would be to relax the assumption that input elements scale proportionally with time. Instead of assuming that the number of intervening neurons between two points in time is constant, it could be assumed that the array consists of $N^{2}$ elements, which is tantamount to assuming that the number of intervening synapses doubles with each unit of time. This would allow the theory to account for a constant CV. In fact, there may be some justification for this relaxed assumption in the planar nature of cerebellar Purkinje cells coupled with their dendritic morphology (Ito, 1984). Parallel fiber inputs to cerebellar Purkinje cells convey timing information according to spreading activation models of timing such as those proposed by Moore, Desmond, and Berthier (1989) and Moore and Choi (1997). The first inputs activated by CS onsets converge near the base of Purkinje cells. Succeeding inputs ascend the planar dendritic tree as time elapses. This structure can implement the squaring of active inputs that occurs with elapsed time.

In conclusion, the results of the present investigation indicate that classical conditioning can help inform research and theory concerning the psychophysics of time. 
There was certainly evidence that the constant CV analogous to Weber's law holds for rabbit eyeblink conditioning across a wide range of ISIs. At the same time, the present results pose a challenge to theoretical models that fail to predict the constancy of the $\mathrm{CV}$.

\section{REFERENCES}

Brelsford, J., JR., \& Theios, J. (1965). Single session conditioning of the nictitating membrane in the rabbit: Effect of intertrial interval. Psychonomic Science, 2, 81-82.

Buonomano, D. V., \& Mauk, M. D. (1994). Neural network model of the cerebellum: Temporal discrimination and the timing of motor responses. Neural Computation, 6, 38-55.

CATANIA, A. C. (1970). Reinforcement schedules and psychophysical judgments: A study of some temporal properties of behavior. In W. N. Schoenfeld (Ed.), The theory of reinforcement schedules (pp. 1-42). New York: Appleton-Century-Crofts.

Cheng, K., \& RoberTs, W. A. (1991). Three psychological principles of timing in pigeons. Learning \& Motivation, 22, 112-128.

Chor, J.-S., \& Moore, J. W. (1994). Asynchronous bilateral eyelid conditioning in rabbits. Society for Neuroscience Abstracts, 20, 1000.

Сhurch, R. M., \& Deluty, M. Z. (1977). Bisection of temporal intervals. Journal of Experimental Psychology: Animal Behavior Processes, 3, 216-228.

Church, R. M., Getty, D. J., \& Lerner. N. D. (1976). Duration discrimination in rats. Journal of Experimental Psychology: Animal Behavior Processes, 2, 303-312.

Church, R. M., Miller, K. D., Meck, W. H., \& Gibbon. J. (199l). Symmetrical and asymmetrical sources of variance in temporal generalization. Animal Learning \& Behavior, 19, 207-214.

Desmond, J. E., \& MoOre, J. W. (1988). Adaptive timing in neural networks: The conditioned response. Biological Cybernetics, $\mathbf{5 8 ,}$ 405-415.

Fetterman, J. G., \& Killeen, P. R. (1992). Time discrimination in Columba livia and Homo sapiens. Journal of Experimental Psychology: Animal Behavior Processes, 18, 80-94.

FREY, P. W., \& MisfeldT, T. J. (1967). Rabbit eyelid conditioning as a function of the intertrial interval. Psychonomic Science, 9, 137-138.

GıвBON, J. (1977). Scalar expectancy theory and Weber's Law in animal timing. Psychological Review, 84, 279-325.

GibBON, J. (1991). Origins of scalar timing. Learning \& Motivation, 22. 3-38.

Gibbon, J., \& Balsam, P. (1981). Spreading association in time. In C. M. Locurto, H. S. Terrace, \& J. Gibbon (Eds.), Autoshaping and conditioning theory (pp. 219-253). New York: Academic Press.

Gormezano, I. (1966). Classical conditioning. In J. B. Sidowski (Ed.), Experimental methods and instrumentation in psychologv (pp. 385420). New York: McGraw-Hill.

Gormezano, I., \& GibBs, C. M. (1988). Transduction of the rabbit's nictitating membrane response. Behavior Research Methods, Instruments, \& Computers, 20, 18-21.

Gormezano, I., Kehoe, E. J., \& Marshall, B. S. (1983). Twenty years of classical conditioning research with the rabbit. In J. M. Sprague \& A. N. Epstein (Eds.), Progress in psychobiologv and physiological psychology (Vol. 10, pp. 197-275). New York: Academic Press.

Grossberg, S.. \& Schmajuk, N. A. (1989). Neural dynamics of adaptive timing and temporal discrimination during associative learning. Neural Networks, 2, 79-102.

INNIS, N. K., \& STADDON, J. E. R. (1971). Temporal tracking on cyclicinterval reinforcement schedules. Journal of the Experimental Analysis of Behavior, 16, $411-423$.

ITO, M. (1984). The cerebellum and neural control. New York: Raven Press.

KEHOE, E. J. ( 1986). Summation and configuration in conditioning of the rabbit's nictitating membrane response to compound stimuli. Journal of Experimental Psychology: Animal Behavior Processes, 12, 186-195.

Kehoe, E. J., Cool, V., \& Gormezano, I. (1991). Trace conditioning of the rabbit's nictitating membrane response as a function of CS-US interstimulus interval and trials per session. Learning \& Motivation. 22, 269-290.

Kehoe, E. J., Horne, A. J., \& Macrae, M. (1995). Learning to learn: Real-time features and a connectionist model. Adaptive Behavior, 3, 235-271.

Kehoe, E. J.. Horne, P. S., Macrae, M., \& Horne, A. J. (1993). Realtime processing of serial stimuli in classical conditioning of the rabbit's nictitating membrane response. Journal of Experimental Psychology: Animal Behavior Processes, 19, 265-283.

KeHOE, E. J., \& NAPIER, R. M. (1991). Temporal specificity in crossmodal transfer of the rabbit nictitating membrane response. Journal of Experimental Psvchology: Animal Behavior Processes, 17, 26-35.

Killeen, P. R., \& Fetterman, J. G. (1988). A behavioral theory of timing. Psychological Review, 95, 274-295.

LeJEUNE, H., \& WEARDEN. J. H. (1991). The comparative psychology of fixed-interval responding: Some quantitative analyses. Learning \& Motivation, 22, 84-111.

Marshall-Goodell. B., Schreurs, B. G., \& Gormezano. I. (1982). Ruler vs. the Apple II/FIRST system analysis of analog signals in classical conditioning. Behavior Research Methods \& Instrumentation, 14, 519-525.

Mis, F. W., Andrews, J. G., \& Salafia, W. R. (1970). Conditioning of the rabbit nictitating membrane response: ISI by ITI interaction. $P s y-$ chonomic Science, 20, 57-58.

MitChell, D. S. (1974). Conditional responding and intertrial-interval variability in classical conditioning in the rabbit (Oryctolagus cuniculus). Journal of Comparative \& Physiological Psvchology, 87, 73-79.

Moore, J. W., \& CHOI, J.-S. (1997). Conditioned response timing and integration in the cerebellum. Learning \& Memory, 4, 116-129.

Moore, J. W., Chol, J.-S., \& Barto, A. G. ( 1996). TD Model of classical conditioning: Response timing and cerebellar implementation. Society for Neuroscience Abstracts, 22, 1643.

Moore, J. W., Choi, J.-S., \& Brunzel., D. H. (1998). Predictive timing under temporal uncertainty: The TD model of the conditioned response. In D. A. Rosenbaum \& C. E. Collyer (Eds.), Timing of hehaviour: Neural. computational, and psychological perspectives (pp. 3-34). Cambridge, MA: MIT Press.

Moore. J. W.. Desmond. J. E., \& Berthier. N. E. (1989). Adaptively timed conditioned responses and the cerebellum: A neural network approach. Biological Cybernetics, 62, 17-28.

Salafia, W. R.. Mis, F. W.. Terry, W. S.. Bartosiak, R. S.. \& Daston, A. P. (1973). Conditioning of the nictitating membrane response of the rabbit (Oryctolagus cuniculus) as a function of length and degree of variation of intertrial interval. Animal Learning \& Behavior, 1. 109-115.

Salafia, W. R., Terry, W., \& Daston, A. P. (1975). Conditioning of the rabbit (Orvctolagus cuniculus) nictitating membrane response as a function of trials per session, ISI, and ITI. Bulletin of the Psychonomic Society, 6, 505-508.

SCHNEIDER, B. A. (1969). A two-state analysis of fixed-interval responding in pigeons. Journal of the Experimental Analysis of Behavior, 12, 677-687.

SMIтH, M. C. (1968). CS-US interval and US intensity in classical conditioning of the rabbit's nictitating membrane response. Journal of Comparative \& Physiological Psychology, 66, 679-687.

Staddon, J. E. R., \& Higa. J. J. (1999). Time and memory: Towards a pacemaker-free theory of interval timing. Journal of the Experimental Analysis of Behavior, 71, 215-25I.

STUBBS, D. A. (1968). The discrimination of stimulus duration by pigeons. Journal of the Experimental Analvsis of Behavior, 11, 223238.

Treisman, M. (1963). Temporal discrimination and the indifference interval: Implications for a model of the "internal clock." Psychological Monographs: General \& Applied, 77 (No. 576).

Wearden, J. H. (1991). Do humans possess an internal clock with scalar timing properties? Learning \& Motivation, 22, 59-83.

ZEILER, M. D. (1991). Ecological influences on timing. Journal of Experimental Psychology: Animal Behavior Processes, 17, 13-25.

(Manuscript received April 25, 2000; accepted for publication August 21, 2000.) 